\title{
2,5-Dihydroxy-3,4-O-isopropylidene-tetrahydrofuran for the synthesis of heterocycles
}

\author{
Marco van denHeuvel, Mick Sayers, and Gurdial Singh ${ }^{*}$ \\ Department of Chemistry, University of Sunderland, Sunderland, SR1 3SD, UK \\ E-mail: gurdial.singh@sunderland.ac.uk
}

Dedicated to Professor Otto Meth-Cohn on the occasion of his $65^{\text {th }}$ birthday

(received 12 May 00; accepted 03 Oct 00; published on the web 11 Oct 00)

\begin{abstract}
2,3-O-isopropylidene-D-ribose was cleaved with sodium metaperiodate to give 1,4-dihydroxy2,3-O-isopropylidenetetrahydrofuran, which underwent a double Wittig reaction on treatment with carboethoxymethylene(triphenyl)phosphorane to give the corresponding dienes. The latter were found to be excellent Michael acceptors and allowed the preparation of pyrrolizidine and tetrahydrothiophene.
\end{abstract}

Keywords: Pyrrolizidine, tetrahydrothiophene, Wittig reaction, heterocycles

\section{Introduction}

The pyrrolizidine alkaloids continue to attract the attention of synthetic chemists and of biologists due to their potent biological effects and the synthetic challenges they represent. In parallel there has been heightened interest in the synthesis of the indolizidine alkaloids ${ }^{1}$ due to the discovery of their antiviral and antitumor activity. The alkaloids castanospermine 1, salaframine 2, and swainsonine 3 are representatives of this class of compound, ${ }^{2}$ and elegant synthetic have been developed to them giving both racemic and, more recently, enantiospecific forms. ${ }^{2}$ 

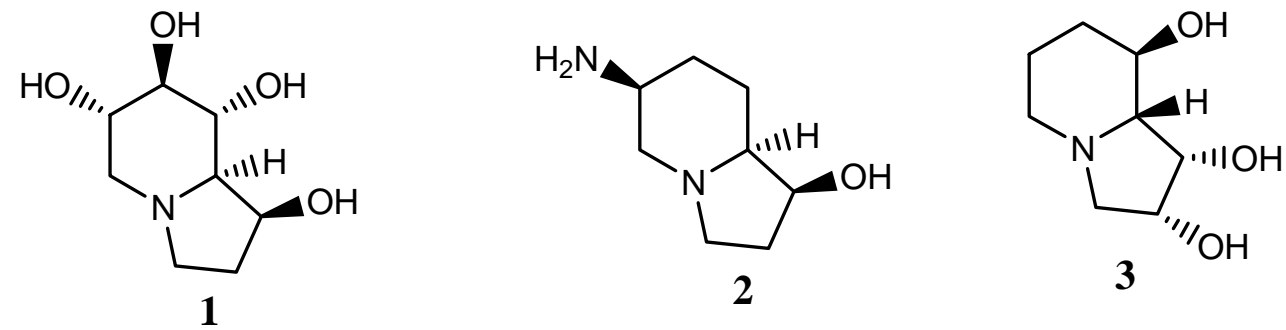

Our interest in the chemistry of carbohydrates led us to consider their use for the synthesis of heterocyclic systems related to these alkaloids. At the forefront of our thinking was the desire to use Wittig chemistry on a carbohydrate derived dialdehyde, and we chose readily available 2,3$O$-isopropylidene-D-ribose as the starting material, a compound that has been used for the synthesis of $C$-glycosyl compounds. ${ }^{3}$ Furthermore relevant chemistry involving Wittig reactions upon 2,3-O-isopropylidene-D-erythrose have been surveyed by Buchanan. ${ }^{4}$

The acetonide 5 was easily prepared by treatment of D-ribose in acetone with a catalytic amount of hydrochloric acid in $85 \%$ yield, after chromatography. The acetonide was cleaved with sodium metaperiodate in water to give the furanose 6 in $60 \%$ yield, after crystallisation from dichloromethane, m.p. $91-92{ }^{\circ} \mathrm{C}$. The furanose 6 exists primarily in the b-form in DMSO solution accompanied by a small amount, $5 \%$, of the all cis-isomer.
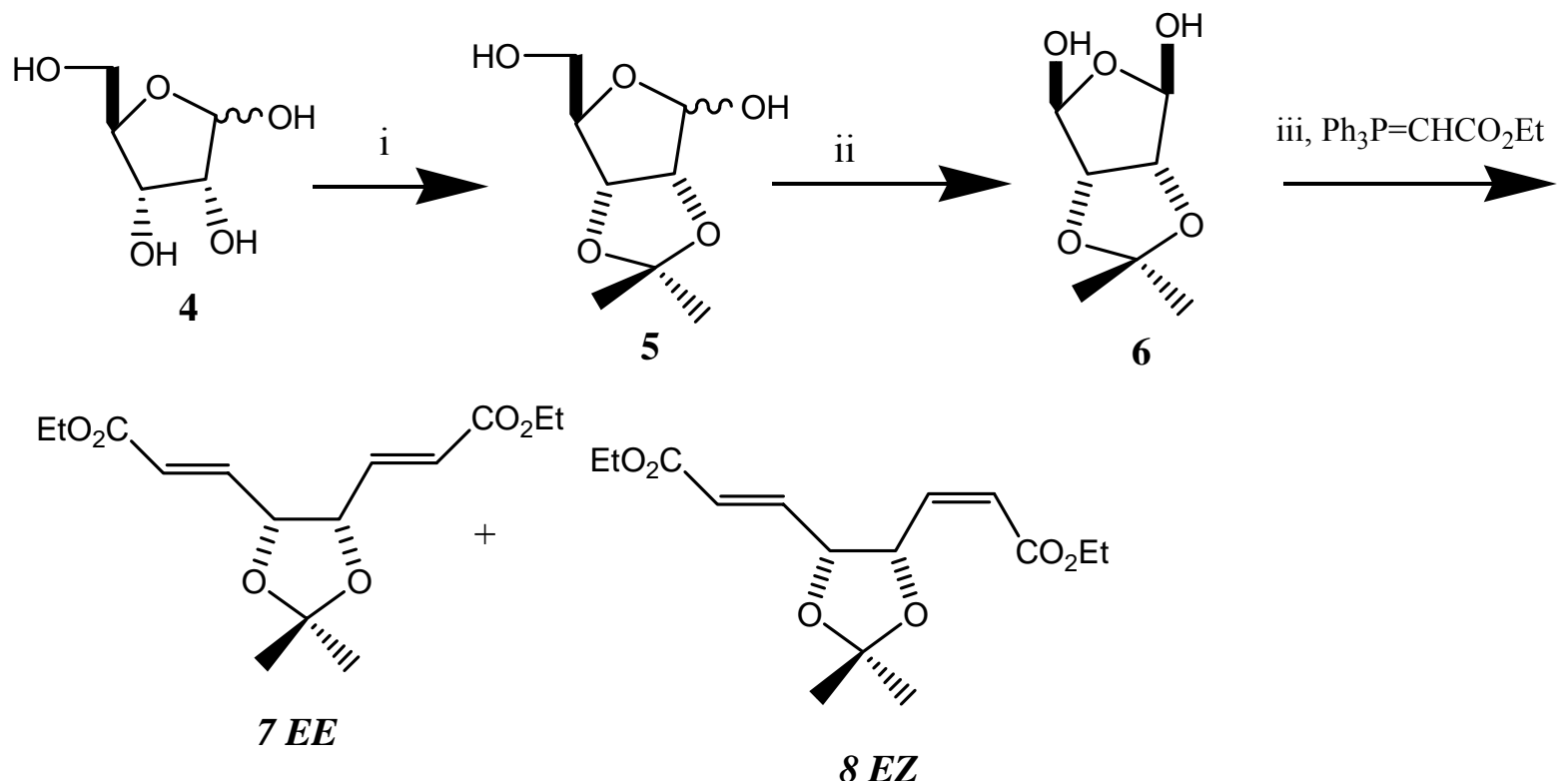

Reagents and Conditions: i, acetone, cat. $\mathrm{HCl}, \mathrm{RT}$, 4h; ii, $\mathrm{NaIO}_{4}, \mathrm{H}_{2} \mathrm{O}, \mathrm{RT}, 3 \mathrm{~h}$; iii, $\mathrm{EtN}\left({ }^{\mathrm{i}} \operatorname{Pr}\right)_{2}(2.2$ eq.), 3 Å mol. sieves, DCM, RT, 4h. 
The dihydroxyfuranose 6 was reacted with ethoxycarbonylmethylene(triphenyl)phosphorane in dichloromethane to give a mixture of $E E$ and $E Z$ alkenes, which were separated by chromatography in a combined yield of $75 \%$ in a ratio of $4: 1$. Analysis of the above crude reaction mixture by ${ }^{1} \mathrm{H}$ n.m.r. and tlc also indicated the presence of the $Z Z$ isomer, however we were unable to obtain any of the isomers in the pure state. The EE geometry of the major component 7 was assigned by ${ }^{1} \mathrm{H}$ n.m.r. spectroscopy. The signals due to $2-\mathrm{H}$ and $3-\mathrm{H}$ showed $J_{2,3} 15.6 \mathrm{~Hz}$ characteristic of a trans-relationship, in addition the spectrum as a whole was simplified as the compound has a plane ofsymmetry. In the spectrum of the EZ isomer 8 two alkenic spin-spin systems are exhibited showing coupling interactions $J_{2,3}=15.5 \mathrm{~Hz}$ and $J_{6,7}=$ $11.6 \mathrm{~Hz}$. In addition, the H-4 signal ( $\delta$ 5.67) appears at a considerably lower field compared to that of H-4 signal in the EE isomer 7 ( $\delta 4.81)$ due to deshielding by the ester carbonyl group.

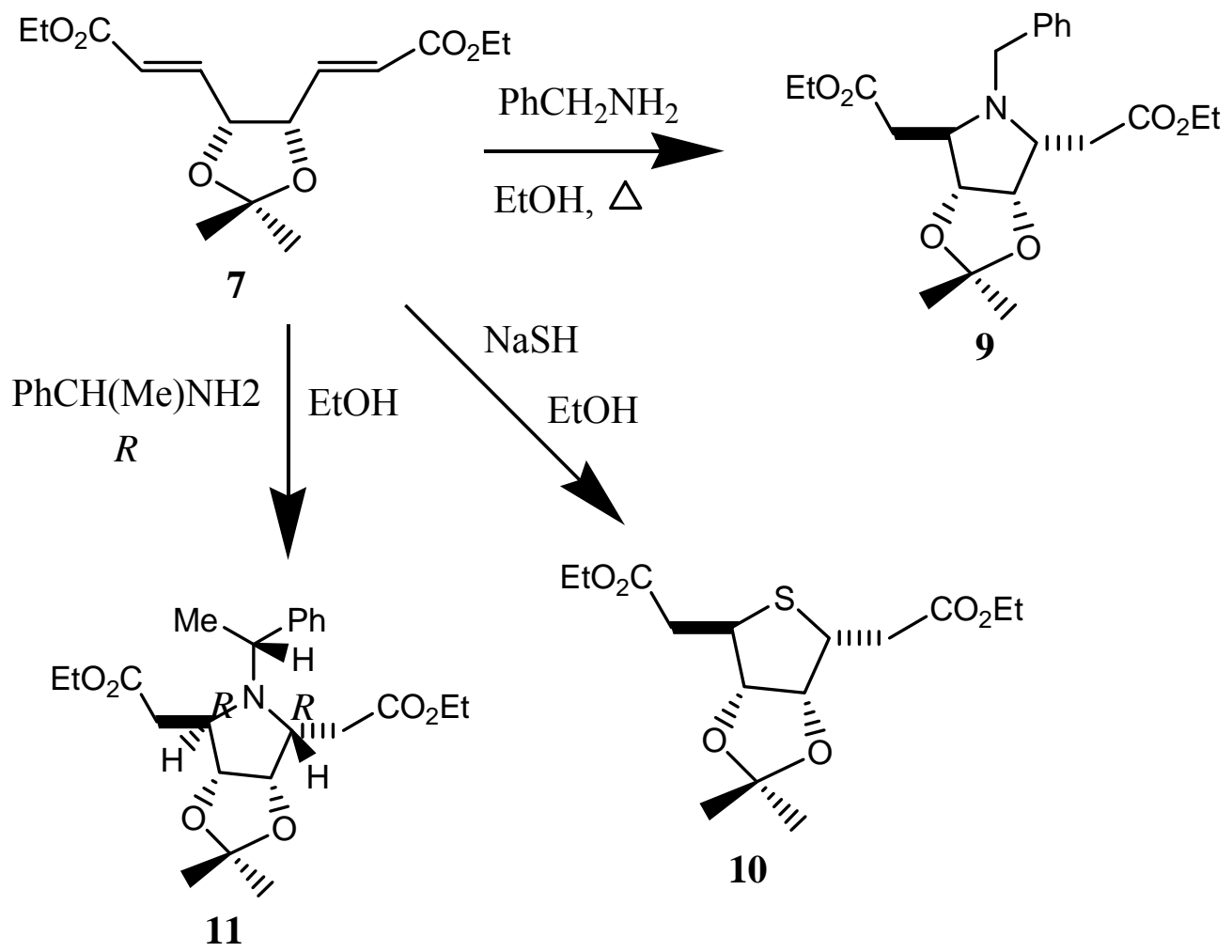

With the dienes 7 and 8 to hand we reacted the $E E$ diene 7 with benzylamine and isolated the racemic pyrrolizidine 9 in 69\% yield as colourless needles. This product has a trans C-2 - C-5 relationship as evidenced by its fully decoupled ${ }^{13} \mathrm{C} \mathrm{nmr}$ spectrum. This shows resonances at $50.60,54.62,60.11,79.07$, whereas for the isomer with a cis orientation at C-2 and C-5 only two resonances in this region would be anticipated. Similarly the ${ }^{1} \mathrm{H} \mathrm{nmr}$ spectrum of the cis product should also be much simplified. 
Following on from this we investigated the reaction of sodium hydrosulfide with 7 , and this resulted in the formation of the racemic tetrahydrothiophene $10 \mathrm{in} 53 \%$ yield. Analysis of the ${ }^{1} \mathrm{H}$ and ${ }^{13} \mathrm{C} \mathrm{nmr}$ of this product also suggested that it had a trans relationship of the hydrogen atoms at C-2 and C-5. Armed with these findings we sought to reintroduce the chirality into these hetereocyclic systems. Both enantiomers of 1-phenylethylamine are commercially available at modest prices. Treatment of the diene 7 with $R$-phenylethylamine resulted in the formation of the pyrrolizidine 11 in a yield of $50 \%$ after chromatographic purification. Once again the relative stereochemistry was found to be trans at C-2 and C-5. Treatment of the S-enantiomer gave the corresponding enantiomeric pyrrolizidine.

In conclusion we have demonstrated that the furanose 6 can be transformed to pyrrolizidines that are capable of elaboration to naturally occurring alkaloids.

\section{Experimental Section}

General methods. ${ }^{1} \mathrm{H}$ NMR spectra were recorded in $\mathrm{CDCl}_{3}$ on Bruker WH $400(400 \mathrm{MHz})$ NMR spectrometer and are reported as follows: chemical shifts $\mathrm{d}(\mathrm{ppm})$, [number of protons, multiplicity, coupling constants $J(\mathrm{~Hz})$, and assignment]. Residual protic solvent $\mathrm{CHCl}_{3}\left(\delta_{\mathrm{H}}=\right.$ $7.26 \mathrm{ppm}$ ) was used as the internal reference. ${ }^{13} \mathrm{C}$ NMR spectra were recorded in $\mathrm{CDCl}_{3}$, at 22.5 $\mathrm{MHz}$ on JEOL EX $90 \mathrm{NMR}$ spectrometer using central resonance of $\mathrm{CDCl}_{3}\left(\delta_{\mathrm{C}}=77.0 \mathrm{ppm}\right)$ as the internal reference. Infra-red spectra were recorded on a UNICAM series FTIR spectrometer. Mass spectra were obtained on a AEI MS 902 or VG ZAB-E spectrometer. Microanalyses were performed by MEDAC Ltd, Surrey. Melting points were determined on a GallenKamp capillary melting point apparatus and are uncorrected. Optical rotations were measured in chloroform solution using Bellingham \& Stanley ADP 220 polarimeter. Flash chromatography was carried out using Fluka silicagel 60 (230-400 mesh) unless otherwise indicated. Analytical thin layer chromatography (TLC) was performed using precoated aluminium plates (Merck Kieselgel 60 $\mathrm{F}_{254}$ ) and visualised by $\mathrm{UV}$, phosphomolybdic acid or basic aqueous potassium permanganate solutions. Petrol refers petroleum ether bp 40-60 ${ }^{0} \mathrm{C}$ which was distilled prior to use and ether $\left(\mathrm{Et}_{2} \mathrm{O}\right)$ refers to diethyl ether.

All reactions were carried out under an argon or nitrogen atmosphere in oven-dried glassware unless otherwise stated. $\mathrm{CH}_{2} \mathrm{Cl}_{2}$ and DMF were distilled from calcium hydride and stored over $4 \AA$ molecular sieves. Aqueous solutions are saturated unless otherwise specified.

1,4-dihydroxy-2,3-O-isopropylidene tetrahydrofuran 6 2,3-O-Isopropylidene-D-ribose (4.88g, $25.7 \mathrm{mmol})$ in water $(80 \mathrm{ml})$ was treated with sodium periodate $(6.6 \mathrm{~g}, 30.8 \mathrm{mmol})$ and the resulting mixture stirred vigorously for $3 \mathrm{~h}$ at room temperature. The mixture was extracted with 
ethyl acetate $(3 \times 100 \mathrm{ml})$, dried over $\mathrm{Na}_{2} \mathrm{SO}_{4}$ and concentrated under reduced pressure to afford a white solid. Crystallisation from dichloromethane gave the title compound as colourless needles $2.85 \mathrm{~g}$, $\left(60 \%\right.$ yield), m. p. $91-92{ }^{\circ} \mathrm{C} . v_{\max }(\mathrm{KBr}) 3452,1386 \mathrm{~cm}^{-1} ; \delta_{\mathrm{H}}\left(400 \mathrm{MHz} ; \mathrm{d}_{6^{-}}\right.$ DMSO) $1.22(3 \mathrm{H}, \mathrm{s}), 1.33(3 \mathrm{H}, \mathrm{s}), 4.51(2 \mathrm{H}, \mathrm{s}), 5.20(2 \mathrm{H}, \mathrm{d}, J 5.3), 6.36(2 \mathrm{H}, \mathrm{d}, J 5.3) ; \delta_{\mathrm{H}}(400$ MHz; $\mathrm{d}_{6}$-DMSO) minor cis isomer, $1.25(3 \mathrm{H}, \mathrm{s}), 1.39(3 \mathrm{H}, \mathrm{s}), 4.51(2 \mathrm{H}, \mathrm{s}), 5.26(2 \mathrm{H}, \mathrm{d}, J 3.4)$, 6.32 (2H, d, J 4.2); $\delta_{\mathrm{C}}\left(22.5 \mathrm{MHz}\right.$; d ${ }_{6}$-DMSO) 24.8, 26.9, 85.2 (2C), 103.3(2C), 111.4; m/z (EI) Found 176.0686 $\mathrm{C}_{7} \mathrm{H}_{12} \mathrm{O}_{5}$ requires 176.0685; micro analysis; Found $\mathrm{C}, 47.81 ; \mathrm{H}, 6.90 \mathrm{C}_{7} \mathrm{H}_{12} \mathrm{O}_{5}$ requires $\mathrm{C}, 47.73 ; \mathrm{H}, 6.87 \%$.

(2E,6E)-Diethyl-4,5-O-isopropylidene-4,5-dihydroxy-2,6-octadienedioate $\quad(7), \quad(2 Z, 6 Z)-$ diethyl-4,5-O-isopropylidene-4,5-dihydroxy-2,6-octadienedioate (8). To a solution of the tetrahydrofuran $6(1.04 \mathrm{~g}, 6 \mathrm{mmol})$ in dichloromethane $(100 \mathrm{ml})$ was added $N, N-$ diisopropylethylamine (1.68g, 2.2 eq.) and ethoxycarbonylmethylene-(triphenyl)phosphorane (4.76g, 2.2 eq.) and $3 \AA$ mol. Sieves (10g). The resultant mixture was stirred at RT for 4 h. The solvent was removed in vacuo and the resultant crude material purified by flash chromatography, silica; (petrol, ether; $2: 1$ ) eluent. This afforded the title compound in a combined yield of $(1.34 \mathrm{~g})$, $75 \%$, ratio $(E E: Z Z, 4: 1)$.

(2E, 6E)-Diethyl-4,5-O-isopropylidene-4,5-dihydroxy-2,6-octadienedioate (7). $v_{\max }$ (neat) $1720,1659 \mathrm{~cm}^{-1} ; \delta_{\mathrm{H}}\left(400 \mathrm{MHz} ; \mathrm{CDCl}_{3}\right) 1.24(6 \mathrm{H}, \mathrm{t}, J 7.1), 1.38(3 \mathrm{H}, \mathrm{s}), 1.53(3 \mathrm{H}, \mathrm{s}), 4.15(4 \mathrm{H}$, q, J 7.1), 4.81 (2H, appt dd, J 2.6, 1.6), $6.04(2 \mathrm{H}, \mathrm{d}, J 15.6), 6.67(2 \mathrm{H}, \mathrm{dd}, J 15.6,1.6) ; \delta_{\mathrm{C}}(22.5$ $\left.\mathrm{MHz} ; \mathrm{CDCl}_{3}\right)$ 13.75, 24.9, 27.2, 60.1, 77.0, 109.8, 123.2, 141.7, 165.1; $1_{\max }(\mathrm{EtOH}, \mathrm{c}=1.31 \mathrm{mg} /$ ml) $268 \mathrm{~nm}$, (e $\left.1.7 \times 10^{2}\right)$; m/z (EI) Found. $298.1424 \mathrm{C}_{15} \mathrm{H}_{22} \mathrm{O}_{6}$ requires 298.1416; microanalysis; Found $\mathrm{C}, 60.35, \mathrm{H}, 7.21 ; \mathrm{C}_{15} \mathrm{H}_{22} \mathrm{O}_{6}$ requires $\mathrm{C}, 60.39 ; \mathrm{H}, 7.43 \%$.

(2Z, 6Z)-Diethyl-4,5-O-isopropylidene-4,5-dihydroxy-2,6-octadienedioate (8). $\delta_{\mathrm{H}}(400 \mathrm{MHz}$; $\left.\mathrm{CDCl}_{3}\right) 1.23(6 \mathrm{H}, 2$ appt. t , J 6.8), $1.36(3 \mathrm{H}, \mathrm{s}), 1.50(3 \mathrm{H}, \mathrm{s}), 4.13(4 \mathrm{H}, \mathrm{m}), 5.02(1 \mathrm{H}, \mathrm{ddd}, J$ 7.4, 5.6, 1.5), 5.63 (1H, dt, J 7.3, 1.6), 5.85 (1H, ddd, J 11.6, 1.7), 6.00 (1H, dd, J 15.5, 1.5), 6.10 $(1 \mathrm{H}, \mathrm{dd}, J 11.6,7.1), 6.62(1 \mathrm{H}, \mathrm{dd}, J 15.6,5.6) ; \delta_{\mathrm{C}}\left(22.5 \mathrm{MHz} ; \mathrm{CDCl}_{3}\right) 14.2(2 \mathrm{C}), 25.1,60.3$, $60.5,76.0,77.4,109.8,12.9,122.6,143.7,146.0,165.5,165.9$.

(5-Ethoxycarbonyl-1-phenylethyl-3,4-O-isopropylidene-pyrrolidin-2-yl)acetic acid ethyl ester (9). To the diene $7(0.76 \mathrm{~g}, 2.5 \mathrm{mmol})$ in ethanol $(5 \mathrm{ml})$ was added benzylamine $(0.297 \mathrm{~g}$, $2.77 \mathrm{mmol}$ ). The was stirred at RT for $0.5 \mathrm{~h}$ and then heated at reflux for $6 \mathrm{~h}$. The volatiles were removed in vacuo to give a pale yellow oil. Dissolution of the residual oil in $10 \mathrm{ml}$ of petrol/ether (2:1) commenced crystallisation of the title compound. The resulting white needles were filtered and dried in vacuo at $30-40{ }^{\circ} \mathrm{C}$. Yield 0.72g, 69\%; m.p. 95-97 ${ }^{\circ} \mathrm{C} . v_{\max }\left(\mathrm{CHCl}_{3}\right) 1732 \mathrm{~cm}^{-1} ; \delta_{\mathrm{H}}$ $\left(400 \mathrm{MHz} ; \mathrm{CDCl}_{3}\right) 1.19(6 \mathrm{H}, \mathrm{t}, J \mathrm{7} .1), 1.28(3 \mathrm{H}, \mathrm{s}), 1.50(3 \mathrm{H}, \mathrm{s}), 2.41$ (2H, appt. dd, J 16.91, 4.0), 2.72 (2H, appt. dd, J 16.9, 4.6), 2.85 (2H, m), 3.67 (2H, s), 4.09 (4H, q, J 7.1), 4.69 (2H, dd, 
$J$ 4.5, 1.4), $7.25(5 \mathrm{H}, \mathrm{m}) ; \delta_{\mathrm{C}}\left(100 \mathrm{MHz} ; \mathrm{CDCl}_{3}\right) 13.92$ (2C), 25.50, 26.06, 33.00, 50.60, 54.62, 60.11, 79.07, 110.94, 128.09, 128.16, 128.41, 171.81; m/z (CI, NH3) $406\left(\mathrm{M}^{+}+\mathrm{H}\right)$; microanalysis; Found C, 65.31; H, 7.89; N, 3.40; $\mathrm{C}_{22} \mathrm{H}_{31} \mathrm{NO}_{6}$ requires $\mathrm{C}, 65.17 ; \mathrm{H}, 7.71 ; \mathrm{N}$, $3.45 \%$.

(5-Ethoxycarbonylmethyl-3,4-O-isopropylidene-tetrahydro-thiopheny-2-yl)acetic acid ethyl ester (10). To a solution of the diene $7(1.05 \mathrm{~g}, 3.52 \mathrm{mmol})$ in ethanol $(10 \mathrm{ml})$ was added $\mathrm{NaSH}$ $(0.21 \mathrm{~g}, 1.1 \mathrm{eq})$. The mixture was stirred at RT for $5 \mathrm{~h}$. The solvent was removed in vacuo and the residue chromatographed using silica, (petrol: ether; 4:1) to afford the title compound as a white solid. Yield 0.62g; 53\%. $v_{\max }\left(\mathrm{CHCl}_{3}\right) 1732 \mathrm{~cm}^{-1} ; \delta_{\mathrm{H}}\left(400 \mathrm{MHz} ; \mathrm{CDCl}_{3}\right) 1.24(6 \mathrm{H}, \mathrm{t}, J \mathrm{~J} .1), 1.26$ $(3 \mathrm{H}, \mathrm{s}), 1.45(3 \mathrm{H}, \mathrm{s}), 2.58$ (2H, appt. dd, $J 16.78,8.34), 2.81$ (2H, appt. dd, $J 16.79,6.34), 3.51$ $3.59(2 \mathrm{H}, \mathrm{m}), 4.11-4.19(4 \mathrm{H}, \mathrm{m}), 4.76(1 \mathrm{H}, \mathrm{d}, J 3.76), 4.77(1 \mathrm{H}, \mathrm{d}, J 1.6) ; \delta_{\mathrm{C}}\left(22.5 \mathrm{MHz} ; \mathrm{CDCl}_{3}\right)$ 13.99 (2C), 24.85, 26.79, 32.69, 33.50, 43.14, 45.73, 60.50, 60.65, 84.49, 85.77, 111.31, 170.53, 171.31; microanalyis; Found C, 54.34; H, 7.42; S, 6.06; $\mathrm{C}_{15} \mathrm{H}_{24} \mathrm{O}_{6} \mathrm{~S}$ requires $\mathrm{C}, 54.20 ; \mathrm{H}, 7.28$; N, 9.64\%.

(5-Ethoxycarbonyl-1-methyl-(1R)-phenylethyl-3,4-O-isopropylidene-pyrrolidin-2-yl)acetic acid ethyl ester (11). To the diene $7(0.76 \mathrm{~g}, 2.55 \mathrm{mmol})$ in ethanol $(5 \mathrm{ml})$ was added $R-(1)$ phenylethylamine $0.4 \mathrm{ml}(0.376 \mathrm{~g}, 3.1 \mathrm{mMol})$. The solution was stirred at RT for $0.5 \mathrm{~h}$ and then heated at reflux for $18 \mathrm{~h}$. The volatiles were removed in vacuo to give a pale yellow oil. The solvent was removed under reduced pressure and the residue chromatographed, silica; (petrol/ether; 2:1). This gave the title compound as a pale yellow oil, decomposition was observed during the purification procedure. Yield $0.53 \mathrm{~g}, 50 \%$; $[\alpha]_{\mathrm{D}}+41\left(\mathrm{c}=0.4, \mathrm{CHCl}_{3}\right) \cdot v_{\max }$ $\left(\mathrm{CHCl}_{3}\right) 1732 \mathrm{~cm}^{-1} ; \delta_{\mathrm{H}}\left(90 \mathrm{MHz} ; \mathrm{CDCl}_{3}\right)$ 1.16-1.24 (6H, m), $1.29(3 \mathrm{H}, \mathrm{s}), 1.49(3 \mathrm{H}, \mathrm{s}), 1.55$ $(3 \mathrm{H}, \mathrm{s}), 2.00-2.45(3 \mathrm{H}, \mathrm{m}), 2.70(1 \mathrm{H}, \mathrm{dd}, J 15.4,4.8), 3.15(1 \mathrm{H}, \mathrm{m}), 4.02-4.25(5 \mathrm{H}, \mathrm{m}), 4.43-4.69$ $(2 \mathrm{H}, \mathrm{m}), 7.21-7.38(5 \mathrm{H}, \mathrm{m}) ; \delta_{\mathrm{C}}\left(22.5 \mathrm{MHz} ; \mathrm{CDCl}_{3}\right)$ 14.08, 18.31, 25.59, 26.10, 34.04, 34.46, 52.86, 53.49, 58.43, 59.99, 60.47, 79.30, 80.37, 111.28, 126.62, 127.00, 128.05, 128.29, 171.94, 172.29; $\mathrm{m} / \mathrm{z}\left(\mathrm{CI}, \mathrm{NH}_{3}\right)$ Found. $437.2657 \mathrm{C}_{23} \mathrm{H}_{37} \mathrm{NO}_{6}$ requires 437.2652.

\section{Acknowledgements}

We thank BASF for financial support and the EPSRC for access to the mass spectrometry service at the University of Wales, Swansea, (Director, Prof. D. E. Games). 


\section{References}

1. (a) Casiraghi, G.; Zanardi, F.; Rassu, G.; Spanu, P. Chem. Rev. 1995, 95, 1677. (b) Michael, J. P. Nat. Prod. Rep. 1997, 619.

2. Asano, N.; Nash, R. J.; Molyneux, R. J.; Fleet, G. W. J. Tetrahedro:n: Asymmetry 2000, 11, 1645.

3. Ohrui, H.; Jones, G. H.; Moffatt, J. G.; Maddox, M. L.; Christensen, A. T.; Byram, S. K. J. Am. Chem. Soc. 1975, 97, 4602.

4. Buchanan, J. G.; Edgar, A. R.; Hewitt, B. D. J. Chem. Soc., Perkin Trans. 1 1987, 2371 and references cited therein.

5. For synthesis of diene of type 7 from L-threitol see: (a) Saito, S.; Hamano, S. I.; Moriyama, H.; Okada, K.; Moriwake, T.; Tetrahedron Lett. 1988, 29,1157, (b) Naito, H.; Kawahara, E.; Maruta, K.; Maeda, M.; Sasaki, S.; J. Org. Chem. 1995, 60; 4419; for ZZ isomer see: Saito, S.; Kuroda, A.; Matsunaga, H.; Ikeda, S.; Tetrahedron 1996, 52, 13919. 